\title{
Perspectives by patients and physicians on outcomes of mid-urethral sling surgery
}

\author{
R. Marijn Houwert • Daphne N. van Munster • Jan Paul W. R. Roovers • \\ Pieter L. Venema • Marcel G. W. Dijkgraaf • Hein W. Bruinse - Harry A. M. Vervest
}

Received: 8 July 2009 / Accepted: 30 October 2009/Published online: 19 November 2009

(C) The Author(s) 2009. This article is published with open access at Springerlink.com

\begin{abstract}
Introduction and hypothesis The aim of this study is to determine patient expectations regarding wanted and unwanted sequels of mid-urethral sling (MUS) procedures and to identify mismatches during the physician-patient information exchange prior to MUS procedures.

Methods A patient preference study (40 patients) and a questionnaire study with 20 experts as control group were conducted. Seventeen different sequels, defined by an expert team, were evaluated.
\end{abstract}

R. M. Houwert · H. A. M. Vervest

Department of Obstetrics and Gynecology,

St. Elisabeth Hospital Tilburg,

Tilburg, The Netherlands

D. N. van Munster $\cdot$ H. W. Bruinse

Department of Obstetrics and Gynecology,

University Medical Centre Utrecht,

Utrecht, The Netherlands

\section{J. P. W. R. Roovers}

Department of Obstetrics and Gynecology,

Academic Medical Centre Amsterdam,

Amsterdam, The Netherlands

P. L. Venema

Department of Urology, Haga Ziekenhuizen,

The Hague, The Netherlands

M. G. W. Dijkgraaf

Department of Clinical Epidemiology and Biostatistics,

Academic Medical Centre Amsterdam,

Amsterdam, The Netherlands

R. M. Houwert $(\bowtie)$

Rooseveltlaan 35 III,

1079 AC Amsterdam, the Netherlands

e-mail: marijnhouwert@hotmail.com
Results Both patients and expert physicians ranked cure and improvement of stress urinary incontinence as the most important goals of treatment. De novo urge urinary incontinence, requiring post-operative intermittent selfcatheterisation and dyspareunia were considered to be the most important complications by patients. Time to resume work after the operation and dyspareunia were among the highest rated sequels in the patient group compared to reoperation and intra-operative complications in the expert group.

Conclusions No differences were found in the five most important outcome parameters. In pre-operative counselling and future clinical trials, time to resume work and dyspareunia should be given more consideration by clinicians.

Keywords Mid-urethral sling surgery

Outcome parameters $\cdot$ Patient expectations

\section{Introduction}

Mid-urethral sling (MUS) procedures are currently the 'gold standard' of surgical treatment for female stress urinary incontinence (SUI) [1]. Cure rates, failure rates and possible complications of different MUS procedures are well-known and thoroughly investigated $[2,3]$. Traditionally, the physician informs the patient prior to surgery about the positive and negative effects to be expected. The information processed by the physician is the selection from all available evidence that he considers of relevance to the patient.

Little is known about how patients value the exchanged information and what additional pieces of information patients would like to see exchanged such as the length of 
hospital stay or time to resume work after the operation. Consequently, little is known about how congruent the expectations of physicians and patients about the course after surgery are.

Medical evaluations that incorporate subjective reporting run the risk of discrepant perceptions between the patient and the physician [4]. For instance, patients and physicians differ considerably by the rating of the severity of urinary incontinence prior to treatment [5]. Also, clinicians tend to be more optimistic when considering outcome following incontinence surgery when compared to patients [6]. Discrepancies between expectations, both in a positive and negative sense, may influence how patients appraise their process of recovery after surgery and perhaps even how they rate the improvements in quality of life to be achieved by MUS procedures.

This study aims to identify mismatches during the physician-patient information exchange prior to MUS procedures by looking at how patients value the information potentially exchanged and whether physicians are aware of those values.

\section{Materials and methods}

A preference study (patients) and a questionnaire study (physicians) were conducted to meet the study objectives. Forty consecutive patients were asked to participate in this investigation, and none of these patients objected. All patients visited the outpatient department in Tilburg or The Hague with complaints of predominant SUI. Patients who underwent previous MUS procedures were excluded. The patients interviewed came for the first time or returned after pelvic floor physiotherapy or drug treatment. They had not discussed surgery in our departments. We provided all patients with similar amounts of information before the interviews.

A history of SUI was defined as the statement of the patient of involuntary leakage during physical activity, coughing or sneezing; urge urinary incontinence (UUI) was defined as the statement of the patient of involuntary leakage when experiencing a feeling of urgency. MUI was considered to be present if both SUI and UUI were reported. Nocturia was defined as a micturition frequency $>1$ during sleep.

All patients agreed to a structured interview with one of the authors (MH, DM and PV). To construct the interview, an expert panel consisting of three urogynaecologists was asked to identify the most prevailing positive (wanted) and negative (unwanted) outcomes associated with MUS surgery. The expert panel was asked to list as many important outcomes as possible after MUS surgery. If an outcome was selected by one of the members of the expert panel, the outcome was investigated in the structured interview (Table 1).

Definitions of the outcome parameters used in the interview were in accordance with the recommendations of the International Continence Society [7]. Incidences were based on our previous study investigating risk factors for failure of MUS procedures [8]. Cure of SUI was defined as not experiencing any loss of urine during physical activity, coughing or sneezing. Improvement was defined as any amount of leakage during physical activity, coughing or sneezing but a substantial gain compared to the preoperative situation. Long-term results available were explained to patients as the availability of 11 years follow-up as described for tension-free vaginal tape [9]. For transobturator tapes, on the other hand, only 3 years follow-up results are available [10]. Re-operation in 1 year was described as a result of failure of the surgical procedure to cure SUI.

Before starting the interviews, the three interviewers agreed on how to conduct the interview and synchronise the information offered to the patients. Before the interview, patients were asked to imagine that they would undergo surgical treatment for their incontinence. During the interview, the outcome parameters were discussed with and explained (if necessary) to the patients by the investigators. Successively, patients were asked to score the outcome parameters for relative importance. A 100-point scoring scale was used to rate the relative importance from 0 (totally

Table 1 Investigated outcome parameters

\begin{tabular}{ll}
\hline & Incidence $^{\mathrm{a}}$ \\
\hline Intra-operative complications & $5 \%$ \\
Duration of hospital admission & 1 day versus longer \\
Post-operative urinary retention & $5 \%$ \\
Cured of SUI after 1 year & $80 \%$ \\
Improvement of SUI & $95 \%$ \\
Long-term results available & $>10$ years \\
Time to resume work after the operation & 6 weeks \\
Voiding difficulty & $6 \%$ \\
De novo UUI & $6 \%$ \\
Necessity of medication to remain continent & $5 \%$ \\
Duration of post-operative pain medication use & 2 weeks \\
Groin pain & $1 \%$ \\
Dyspareunia & $1 \%$ \\
Post-operative intermittent self-catheterisation & $2 \%$ \\
Re-operation in 1 year & $2 \%$ \\
Urinary tract infection & $1 \%$ \\
Tape erosion & $2 \%$ \\
\hline
\end{tabular}

${ }^{\mathrm{a}}$ Own results described in reference [8] 
unimportant) to 100 (utmost importance). Patients were asked to score on five points punctual. The basic format of the structured interview is provided in the Appendix.

To identify possible differences in relative importance between patients and physicians, we sent a questionnaire modification of the structured interview by email to 25 opinion-leaders (experts) in the field of urogynaecology in the Netherlands and Belgium. Experts were defined as gynaecologists or urologists who on weekly basis treat patients with SUI. This expert panel was used as the comparison group. The experts were asked to score the 17 outcome parameters for the relative importance they thought would represent the opinion of their patients. The same 100-point scale was used for scoring.

Mann-Whitney $U$ tests were performed to compare the scores of patients and experts for each of the 17 outcome parameters. A $p$ value of less than 0.05 was considered to represent statistical significance. The primary goal of this study was to determine patient expectations regarding possible outcomes after MUS surgery. Cure and improvement of SUI are likely to be ranked among the top five most important outcome parameters after MUS procedures. Therefore, we also selected the five 'other' most important outcome parameters in each group and ranked a 'top 7'.

Statistical analysis was performed with Statistical Package for the Social Sciences (Windows version 15.0). This study was approved by the Medical Ethical Committee of the St. Elisabeth Hospital.

\section{Results}

Baseline characteristics of the patient population are described in Table 2. All patients with MUI were predominantly stress-incontinent. Two patients underwent previous incontinence surgery (Burch colposuspension).

Table 3 shows the results of the investigated outcome parameters in the patient and expert groups. Twenty $(80 \%)$ experts returned the questionnaire.
No differences were found in the five most important outcome parameters. Both patients and experts ranked cure and improvement of SUI as most important outcome parameters. Also, the importance of long-term follow-up results is recognised in both groups. Most relevant complications for patients were de novo UUI, postoperative intermittent self-catheterisation and dyspareunia.

Differences in 'top 7' were time to resume work after the operation and dyspareunia in the patient group and reoperation and intra-operative complications in the expert group. Although both patient and experts ranked cure and improvement as most important outcomes, patients' raw values were higher than the ones from the experts $(p<0.01$ and $p=0.02$, respectively). Patients valued time to resume work after the operation as more relevant than experts $(p<0.01)$.

\section{Discussion}

The aims of this study were to determine patient expectations regarding possible wanted and unwanted outcomes of MUS procedures and identify possible mismatches during the physician-patient information exchange prior to MUS procedures. The experts were asked to score the outcome parameters in the opinion of their patients. Although not totally natural, physicians expect themselves to think for their patients in daily practice. As might be expected, cure and improvement of SUI were considered the most important outcome parameters after MUS procedures. Most relevant complications for patients were de novo UUI, requiring postoperative intermittent self-catheterisation and dyspareunia.

An important goal of this study was to find differences between patients and physicians. Before elaborating on this issue, it is reassuring that patients and physicians agree on the most important issues like cure, improvement and functional complications.

A remarkable difference is that patients are generally more concerned about parameters which influence quality of life (time to resume work after the operation and
Table 2 Baseline characteristics of patient population

\begin{tabular}{llrl}
\hline Age (years, mean (range)) & & 55 & $(33-78)$ \\
Parity $(n$, mean $($ range) $)$ & & 2 & $(0-4)$ \\
Type of incontinence $(n(\%))$ & SUI & 32 & $80 \%$ \\
& MUI & 8 & $20 \%$ \\
Frequency of incontinence $(n(\%))$ & Daily episodes & 38 & $95 \%$ \\
& Weekly episodes & 2 & $5 \%$ \\
Duration of incontinence (months, mean (range)) & & 49 & $(3-120)$ \\
Daily micturition frequency $(n$, mean (range)) & & 8 & $(3-15)$ \\
Nocturia $(n(\%))$ & & 12 & $30 \%$ \\
Underwent pelvic floor physiotherapy $(n(\%))$ & 24 & $60 \%$ \\
Used medication for incontinence $(n(\%))$ & 8 & $20 \%$ \\
\hline
\end{tabular}


Table 3 Scores of patients and experts

\begin{tabular}{|c|c|c|c|c|c|c|c|}
\hline & \multicolumn{3}{|c|}{ Patient scores } & \multicolumn{3}{|c|}{ Expert scores } & \multirow[t]{2}{*}{$p$ value $^{\mathrm{a}}$} \\
\hline & Median & Interquartile range & Rank & Median & Interquartile range & Rank & \\
\hline Intra-operative complications & 65 & $30-80$ & & 65 & $40-90$ & 7 & 0.65 \\
\hline Duration of hospital admission & 55 & $11-98$ & & 28 & $20-48$ & & 0.09 \\
\hline Post-operative urinary retention & 55 & $21-84$ & & 60 & $50-74$ & & 0.56 \\
\hline Cured of SUI after 1 year & 100 & $100-100$ & 1 & 97 & $81-100$ & 1 & $<0.01$ \\
\hline Improvement of SUI & 100 & $90-100$ & 2 & 93 & $80-100$ & 2 & 0.02 \\
\hline Long-term results available & 80 & $71-100$ & 5 & 75 & $50-88$ & 5 & 0.06 \\
\hline Time to resume work after the operation & 75 & $50-100$ & 6 & 40 & $20-60$ & & $<0.01$ \\
\hline Voiding difficulty & 70 & $33-80$ & & 70 & $60-80$ & & 0.45 \\
\hline De novo UUI & 90 & $63-100$ & $3^{\mathrm{b}} 4$ & 75 & $60-90$ & 4 & 0.16 \\
\hline Necessity of medication to remain continent & 30 & $10-60$ & & 35 & $20-50$ & & 0.98 \\
\hline Duration of post-operative pain medication use & 35 & $10-60$ & & 30 & $10-56$ & & 0.73 \\
\hline Groin pain & 50 & $20-70$ & & 35 & $20-50$ & & 0.38 \\
\hline Dyspareunia & 73 & $45-90$ & 7 & 58 & $40-70$ & & 0.10 \\
\hline Post-operative intermittent self-catheterisation & 90 & $63-100$ & $3^{\mathrm{b}} 4$ & 80 & $63-90$ & 3 & 0.14 \\
\hline Re-operation in 1 year & 65 & $21-80$ & & 65 & $50-90$ & 6 & 0.29 \\
\hline Urinary tract infection & 28 & $10-60$ & & 20 & $10-30$ & & 0.07 \\
\hline Tape erosion & 50 & $10-80$ & & 60 & $30-80$ & & 0.31 \\
\hline
\end{tabular}

${ }^{\text {a } M a n n-W h i t n e y ~} U$ test

${ }^{\mathrm{b}}$ Ex aеquo

dyspareunia), while experts tend to overestimate the value of more technical parameters (risk on re-operation and risk on intra-operative complications). An explanation for this difference could be found during the interviews. In general, patients told us that they might be willing to accept the risk of intra-operative complications or a re-operation to solve their incontinence problem if counselled properly.

As SUI is a significant quality of life issue and treatment is usually elective, it is imperative to determine patient's expectations of outcome [11]. Treatment options can be adjusted to patient preferences, and pre-operative counselling can be improved. Therefore, expanding knowledge of patient expectations may improve treatment results. Furthermore, outcome parameters that are considered important by patients should become main goals of studies investigating results of MUS surgery.

Other studies addressing expectations of women being evaluated for lower urinary tract symptoms used different measures of bother and quality of life including the incontinence quality of life measurement and the King's health questionnaire $[12,13]$. These quality of life questionnaires do not always contain the relevant questions and, contrary to this study, might fail to identify which outcome parameters are important for patients. In this study, outcome parameters from daily clinical practice were used, and women were asked to add important outcomes if missing. Therefore, results of this study provide a complete overview of women's expectations regarding counselling before MUS surgery.

A possible drawback of the study design is that only three experts selected the rated outcome parameters. However, both patients and experts were asked if they missed important outcome parameters in the presented list. None of the patients or experts missed an important outcome parameter. Therefore, it is plausible that the most important outcome parameters were scored. Another drawback of this study is that the patients were interviewed by three different persons, which might induce a bias. However, as a structured interview was used, little opportunities were available for the interviewers to influence patient scores.

Another possible disadvantage of this study design is that patients could theoretically score all parameters equally (for example, 50). To assess the presence of such response patterns at individual patient level in the present data set, we analysed the scoring range for each participant. We calculated the differences between the highest and the lowest score for each patient. The range of these differences was 40 (minimal) to 100 (maximal). Therefore, the response patterns indicate considerable differentiation in valuation by individual patients.

A possible bias is differences between patients. Some patients asked many questions about possible consequences of the discussed outcome parameters, others did not. However, in common daily practice, these differences between patients are also present. 
Two patients had previous colposuspensions, which might be a source of bias as their expectations would have been altered by having previous, failed incontinence surgery. However, as they underwent surgery in the eighties (1984 and 1988) and for more than 20 years remained continent, surgery did not fail in their perception.

A formal power analysis was considered inappropriate in absence of any useful prior data on relative weights attached to MUS outcome parameters by patients and by experts asked to reflect on patients' opinions. The included number of 40 patients and 20 experts and the application of distribution-free statistics of ranks, however, should be sufficient to generate a first assessment of potential mismatches. For instance, although patients and experts ranked cure and improvement equally high, the differences in absolute valuations (medians: 100 versus 97; 100 versus 93, respectively) suggest that experts should realise that the importance of cure and improvement cannot be overestimated.

SUI is more common in young and middle-aged women, who are more likely to work and to be sexually active [14]. Results of our study indicate that patients considered both parameters of significant importance. Currently, no data are available about time to resume work after the operation and, consequently, this parameter should be an important outcome parameter in future clinical trials.

It has been largely demonstrated that urinary leakage can have a dramatic effect on the quality of female sexual life, and it can even lead to a complete lack of sexual activity in a high proportion of cases [15]. Our results confirm these findings and show that patients consider sexual function very important. Therefore, physicians should not underestimate the impact of the surgical procedure on the sexual well-being of the patient.

Another important observation is that the availability of long-term results ( $>10$ years) are recognised as an important parameter by both patients and experts. Nowadays, patients want to know if the recommended surgical procedure achieved satisfying long-term results. Therefore, it is remarkable that obturator tapes are performed on large scale while little evidence is available of results after only 3 years of follow-up $[10,16]$. Furthermore, follow-up of the available prospective comparative trials between obturator tapes and the current 'gold standard' (tension-free vaginal tape) does not exceed a 1-year period $[2,3,16]$. Results of this study once again emphasise the need for long-term trials of obturator tapes.

\section{Conclusion}

Experts and patients agree on the importance of cure and improvement of SUI, de novo UUI and post-operative intermittent self-catheterisation as potential complications as well as recognising the importance of long-term follow-up data. Time to resume work after the operation and dyspareunia were among the highest rated sequels in the patient group compared to re-operation and intra-operative complications in the expert group. In pre-operative counselling and future clinical trials, time to resume work after the operation and dyspareunia should be regarded.

\section{Conflicts of interest None.}

Open Access This article is distributed under the terms of the Creative Commons Attribution Noncommercial License which permits any noncommercial use, distribution, and reproduction in any medium, provided the original author(s) and source are credited.

\section{Appendix}

Basic format of the interview

Q1: How important on a scale from 0 to 100 do you consider being counselled about the possibility of intraoperative complications?

E1: Intra-operative complications are side effects during the surgical procedure which occur unexpectedly like bladder or urethral injury, bleeding or perforation of the bowel. Our previous results indicated that these complications occurred in 5\% of the patients who underwent surgery.

Q2: How important on a scale from 0 to 100 do you consider being counselled about the duration of the hospital admission?

E2: Our former study indicated that most patients go home the same day or stay one night.

Q3: How important on a scale from 0 to 100 do you consider being counselled about the possibility of postoperative urinary retention?

E3: Urinary retention is the impossibility to void for which an indwelling catheter for more than $24 \mathrm{~h}$ is necessary. In most cases, the indwelling catheter can be removed within 3 days. Our former study indicated that this condition occurred in $5 \%$ of the patients.

Q4: How important on a scale from 0 to 100 do you consider being counselled about expected cure rates after the surgical procedure?

E4: Cure is defined as absolutely no loss of urine during coughing sneezing or physical activity. Normally $80 \%$ of the patients are cured after 1 year.

Q5: How important on a scale from 0 to 100 do you consider being counselled about improvement after the surgical procedure?

E5: Improvement is defined as sometimes loss of urine during coughing sneezing or physical activity. However, the situation is improved compared to the situation pre- 
operatively. Normally, $95 \%$ of the patients report improvement after 1 year.

Q6: How important on a scale from 0 to 100 do you consider being counselled about the availability of longterm results of a surgical procedure?

E6: For example, there are two basic surgical procedures. For the first procedure, tension-free vaginal tape, results are available 11 years after surgery. For the second procedure, transobturator tape, results are available after 3 years.

Q7: How important on a scale from 0 to 100 do you consider being counselled about time to resume work after the surgical procedure?

E7: Our former studies showed that nearly all patient resumed work after 6 weeks. The majority was able to return to work after 2 weeks.

Q8: How important on a scale from 0 to 100 do you consider being counselled about the possibility of voiding difficulty after the surgical procedure?

E8: Voiding difficulty is defined as micturition that becomes more difficult as a result of the operation. Normally, micturition takes longer; in rare cases, the tape needs to be removed. Our former studies indicated that voiding difficulty occurred in $6 \%$ of the patients.

Q9: How important on a scale from 0 to 100 do you consider being counselled about the possibility of de novo urge urinary incontinence after the surgical procedure?

E9: Urge incontinence is described as loss of urine preceded by feelings of (strong) urgency. In some cases, the stress incontinence is cured, but after the operation, urge incontinence develops. Our previous studies indicated that de novo urge incontinence occurred in $6 \%$ of the patients.

Q10: How important on a scale from 0 to 100 do you consider being counselled about the necessity to use medication to remain continent after the operation?

E10: Our previous studies indicated that $5 \%$ of the patients needed daily medication to remain continent.

Q11: How important on a scale from 0 to 100 do you consider being counselled about the duration of postoperative pain medication?

E11: Our previous studies indicated that patients needed post-operative medication for maximal of 2 weeks.

Q12: How important on a scale from 0 to 100 do you consider being counselled about the possibility of postoperative groin pain?

E12: In some cases, groin pain develops after the operation. Normally, groin pain resolves within 6 weeks, but in our population, two cases are known were groin pain existed after 6 months.

Q13: How important on a scale from 0 to 100 do you consider being counselled about the possibility of dyspareunia?

E13: Dyspareunia is pain or discomfort during sexual intercourse. In our population, $1 \%$ of the patients developed dyspareunia after the operation.
Q14: How important on a scale from 0 to 100 do you consider being counselled about the possibility of postoperative intermittent self-catheterisation?

E14: Post-operative intermittent self-catheterisation is necessary when a patient is unable to micturate spontaneously after the operation. Patients are learned to perform the catheterisation at home. In our population, self-catheterisation was necessary in $1 \%$ of the patients.

Q15: How important on a scale from 0 to 100 do you consider being counselled about the possibility of a reoperation in 1 year?

E15: A re-operation in 1 year is necessary if the first operation fails. In our population, $2 \%$ of the patients needed a re-operation within 1 year.

Q16: How important on a scale from 0 to 100 do you consider being counselled about the possibility of developing a urinary tract infection after the operation?

E16: In our population, $1 \%$ of the patients developed a urinary tract infection.

Q17: How important on a scale from 0 to 100 do you consider being counselled about the possibility of a tape erosion?

E17: When the tape protrudes through the vaginal wall, it is called an erosion. When an erosion occurs, the protruding part of the tape needs to be removed. Tape erosions occurred in $2 \%$ of our patient population.

Q: question

E: explanation

\section{References}

1. Serati M, Salvatore S, Uccella S, Artibani W, Novara G, Cardozo L et al (2009) Surgical treatment for female stress urinary incontinence: what is the gold-standard procedure? Int Urogynecol J Pelvic Floor Dysfunct 20:619-621

2. Latthe PM, Foon R, Toozs-Hobson P (2007) Transobturator and retropubic tape procedures in stress urinary incontinence: a systematic review and meta-analysis of effectiveness and complications. BJOG 114:522-531

3. Sung VW, Schleinitz MD, Rardin CR, Ward RM, Myers DL (2007) Comparison of retropubic vs transobturator approach to midurethral slings: a systematic review and meta-analysis. Am J Obstet Gynecol 197(1):3-11

4. Melville JL, Walker E, Katon W, Lentz G, Miller J, Fenner D (2002) Prevalence of comorbid psychiatric illness and its impact on symptom perception, quality of life, and functional status in women with urinary incontinence. Am J Obstet Gynecol 187(1):80-87

5. de Boer TA, Gietelink DA, Vierhout ME (2008) Discrepancies between physician interview and a patient self-assessment questionnaire after surgery for pelvic organ prolapse. Int Urogynecol J Pelvic Floor Dysfunct 10:1349-1352

6. Black N, Griffiths J, Pope C, Bowling A, Abel P (1997) Impact of surgery for stress incontinence on morbidity: cohort study. BMJ 315:1493

7. Abrahams P, Cardozo L, Fall M, Griffiths D, Rosier P, Ulmsten U (2002) The standardization of terminology of the lower urinary tract function. Report from the standardization subcommittee of the international continence society. Neurourol Urodyn 21:167-178 
8. Houwert RM, Venema PL, Aquarius AE, Bruinse HW, Kil PJM, Vervest HAM (2009) Predictive value of urodynamics on outcome of midurethral sling surgery for female stress urinary incontinence. Am J Obstet Gynecol 200:649.e1-649.e12

9. Nilsson CG, Palva K, Rezapour M, falconer C (2008) Eleven years prospective follow-up of tension-free vaginal tape procedure for treatment of stress urinary incontinence. Int Urogynecol J Pelvic Floor Dysfunct 19(8):1043-1047

10. Houwert RM, Renes C, Vos MC, Vervest HAM (2009) TVT-O versus Monarc after a 2-4 year follow-up: a prospective comparative study. Int Urogynecol J Pelvic Floor Dysfunct 20:1327-1333

11. Langford CF, Elmissiry MM, Ghoniem GM (2009) Do women have realistic expectations of treatment for stress urinary incontinence? Neurourol Urodyn 27:480-484

12. Kelleher CJ, Cardozo LD, Khullar V et al (1997) A new questionnaire to assess the quality of life of urinary incontinent women. Br J Obstet Gynaecol 104:1374-1379
13. Robinson D, Anders K, Cardozo L et al (2003) What do women want? Interpretation of the concept of cure. J Pelvic Med Surg 9:273-277

14. Hannestad YS, Rortveit G, Sandvik H, Hunskaar S (2000) Norwegian EPINCONT study. Epidemiology of Incontinence in the County of Nord-Trøndelag. A community-based epidemiological survey of female urinary incontinence: the Norwegian EPINCONT study. Epidemiology of Incontinence in the County of Nord-Trøndelag. J Clin Epidemiol 53(11):1150-1157

15. Serati M, Salvatore S, Uccella S, Zanirato M, Cattoni E, Nappi RE, Bolis P (2009) The impact of the mid-urethral slings for the treatment of stress urinary incontinence on female sexuality. J Sex Med 6:1534-1542

16. Waltregny D, Gaspar Y, Reul O, Hamida W, Bonnet P, de Leval J (2008) TVT-O for the treatment of female stress urinary incontinence: results of a prospective study after a 3-year minimum follow-up. Eur Urol 53(2):401-410 